\title{
Understanding Australian Aboriginal Tertiary Student Needs
}

\author{
Rhonda Oliver ${ }^{1}$, Judith Rochecouste ${ }^{2}$, Debra Bennell ${ }^{3}$, Roz Anderson ${ }^{4}$, Inala Cooper ${ }^{2}$, Simon Forrest $^{1} \&$ Mike Exell $^{1}$ \\ ${ }^{1}$ Curtin University, Perth, Australia \\ ${ }^{2}$ Monash University, Melbourne, Australia \\ ${ }^{3}$ University of New England, Armidale, Australia \\ ${ }^{4}$ Charles Darwin University, Darwin, Australia \\ Correspondence: Judith Rochecouste, Office of the Pro Vice Chancellor Learning \& Teaching, Monash University, \\ Melbourne, Australia. Tel: 61-4120-4806 E-mail: Judith.Rochecouste@monash.edu
}

Received: September 12, 2013

Accepted: September 27, 2013

Online Published: October 7, 2013

doi:10.5430/ijhe.v2n4p52

URL: http://dx.doi.org/10.5430/ijhe.v2n4p52

\begin{abstract}
Drawing from a study of the experiences of Australian Aboriginal and Torres Strait Islander university students, this paper presents an overview of the specific needs of these students as they enter and progress through their tertiary education. Extracts from a set of case studies developed from both staff and student interviews and an online survey are used to illustrate what we have categorised as the emotional, motivational, financial, study, literacy, and transitional needs of this particular cohort of students.

Our findings, supported strongly by other current research, point to the need for a whole-of-university approach to enhancing the educational and subsequent employment opportunities for Aboriginal students. This includes acknowledging cultural and familial responsibilities, recognising and accommodating Aboriginal knowledge, and ensuring equitable experiences of university life.
\end{abstract}

Keywords: Aboriginal higher education, Indigenous higher education, Indigenous transition, Indigenous student experience

\section{Introduction}

In this paper we focus on the specific needs of Australian Aboriginal (Note 1) university students and how these needs might be addressed. To do this we draw on data collected for a large scale study entitled The Transition of Aboriginal and Torres Strait Islander Students into Higher Education project (Note 2) (Oliver et al 2013). The study was conducted at four participating Australian universities and data were also collected by way of an online survey made available to Aboriginal students nationwide.

There is now an extensive body of research addressing Aboriginal and Torres Strait Islander (Note 3) education and a growing number of studies focusing on Aboriginal students in the tertiary education sector. Not surprisingly, many are reiterating calls for improvement in Aboriginal academic success and completion (Devlin, 2009; Anderson, 2012) and the end to stereotyping and racism (Sonn, Bishop and Humphries, 2000). All these studies acknowledge the underrepresentation of Aboriginal students in Australian universities (Department of Education, Employment and Workplace Relations, 2009; Pechenkina \& Anderson, 2012) and most describe the difficulties under which this student cohort manages to study for a degree. For example, they describe how Aboriginal students face daunting financial constraints, ongoing familial responsibilities, and frequent health and housing concerns (Andersen, Bunda \& Walter, 2008; Australian Council for Educational Research (ACER), 2011) which inevitably lead to non-completion for many (Brady, 2012). Potential strategies to increase Aboriginal student numbers have been suggested in the literature including the involvement of secondary schools and structural changes to universities. These strategies relate to student support, staffing and the content and nature of the courses offered.

The most obvious support structures for students are the Aboriginal centres that have been established within Australian universities nationwide. These are described as providing essential support such as help with transition and orientation processes (e.g., DiGregorio, Farrington \& Page, 2000; Bin-Sellik, 2003; Rogers-Falk, 2012; \& Herbert, 2005). The centres also provide assistance and a 'safe haven' for new and more experienced students (Brady, 2012), both in terms of preparation for study and ongoing learning, but also in relation to helping students address financial, social, emotional and cultural needs. 
The centres can also play a proactive role in recruiting more Aboriginal students to university. However, since their inception in the 1970s, the success of this recruitment has fluctuated, and in recent times several authors have called for greater contact between centres and secondary schools, particularly given the increasing numbers of Aboriginal students who are now achieving high school graduation (Devlin, 2009; James et al., 2008). Clearly these centres have important and strategic roles to fulfil, however, as Anderson (2012) indicates, they suffer from both mounting demands and shrinking resources.

In addition to university Aboriginal centres, universities need to consider other mechanisms to attract and support Aboriginal students, for example, increases in Aboriginal academic staff numbers (Andersen et al., 2008; Rigney, 2012) with a concurrent increased focus on Aboriginal post-graduate enrolments (Barney, 2013) (in that these students can fill staff positions in the future).

Attention has also been given to the curriculum and its delivery in universities. Numerous scholars have addressed the lack of Indigenous knowledge that is being incorporated into university courses and are critical of the ad hoc way in which Indigenous knowledge is recognised (Nakata, 2006, 2007; Walter, 2012). In a similar vein, specific Indigenous learning approaches and styles have been identified although these claims have become somewhat contentious (see for example Anderson, 2000; Malcolm \& Rochecouste 2002; Stewart, 2002). Universities have also been the target of criticism because they have failed to recognise diversity among Aboriginal students, particularly in relation to their enrolment procedures and chosen courses. For example, Oliver et al (2013) highlight the change that has occurred in Aboriginal student course demand - it is no longer appropriate to assume that health and education courses are the primary targets: more Aboriginal students are interested in and are beginning to enrol in areas such as engineering, law and business.

Overall there is a unanimous call for an improvement in Aboriginal staff and student representation within Australian universities, with most researchers indicating that this will only occur when a university-wide approach is applied. Particular attention should be given to Aboriginal student transition into university life in ways that enable their unique needs to be appropriately addressed. In order to do this there is need to identify these needs - hence the aim of the current research.

\section{Method}

Data for this project were collected in two stages using both qualitative and quantitative methods. During stage one, 25 staff and 56 students from the four participating universities made themselves available for an in depth interview or a focus group discussion with a research team member (Note 4). Off campus students made themselves available for a telephone interview. Other students preferred to be interviewed with a friend, and 10 students took part in a focus group discussion. For reasons around cultural and personal sensitivities, interviews were not recorded but careful field notes were taken and quotes, with the interviewees' permission, recorded verbatim. An incentive of a gift voucher for a local chain store was offered to student interviewees. The teaching and support staff interviewed for our study provided evidence of their own responses to students' needs, their teaching experiences, and for many, their own experiences as students, which supported much of what the students related in their interviews.

Thematic analysis of these data focusing on evidence of success and of concern was performed and subsequently reviewed by the research team which included four Aboriginal persons who have worked extensively with Aboriginal students in higher education. A set of 15 survey questions, informed by the data, was then developed by the team for online distribution through university Aboriginal centres across Australia. Both opened-ended and closed questions were included to capture demographic data and opinions and experiences, and to triangulate the interview data. Some 96 responses were received providing a rich source of experiential evidence through open-ended questions. To attract responses, a competition for one of three iPads was set up and managed by the web developers, that is, independently of the research team. This constituted stage two of the data collection.

Finally a report and website were prepared to disseminate the findings of the project and a set of twelve recommendations were developed by the team to inform future university policy-making.

Clearly there are limitations to our research. The low numbers of respondents to the survey represent only a small portion of the total Australian Aboriginal student population. Nonetheless, we were provided with valuable data which substantiated our findings from stage one. On the other hand, we were overwhelmed at the willingness of students to be interviewed. It is possible that our incentive, which would enable the purchase of groceries, clothing, etc., was a strong attraction for those students at some of the participating universities who are financially constrained. It should be noted, that at those universities within major cities, our student cohort was more representative of the middle classes. 


\section{Result and Discussion}

In terms of student need, the most pronounced to emerge in our study was the need for ongoing support. Such support, however, was required in response to a wide range of needs which we have categorised as: emotional, motivational, financial, study, literacy, and transitional needs. In the following sections block quotes have been taken from our set of case studies (stories), and verbatim quotes from interviews and open-ended survey questions are marked with inverted commas.

\subsection{Emotional needs}

Emotional needs include those stresses that students face as a result of their Aboriginality. For example, some students were seen as dealing with an 'intergenerational anger or sadness' (see Stephen's story below) and the need for this to be worked through:

Stephen [a research fellow and former teacher at his University's Aboriginal centre] has experienced angry students - 'an intergenerational anger or sadness' but claims that 'we are all manifestations of those legacies they are hard to tap into, lead to attrition and deflection of deadlines... some of these students are dealing with issues and the history of colonization, so it is frustrating at first to get through the baggage'.

For those Aboriginal students (and staff) who enrol in courses that cover Aboriginal history 'some of the content hits home', and many will go through a series of reactions as they learn about past policies and the treatment of their people (see Lorraine's story below):

Lorraine [a lecturer in an Aboriginal Education unit] observes that .... going through reactions to the past is a process that most Aboriginal staff and students will experience - 'First it's "Oh my God, did that happen?", then it's anger, then it's grief, and then it's either activism or acceptance'.

It is common that some Aboriginal students are the first in their family to attend university and this places huge expectations on them. Sometimes they are expected to immediately become spokespersons for their community or a representative for their family and are called upon to write letters to government agencies and the like. Such tasks require a relatively high-level of literacy - resulting in additional stress (see Rhoda's story below):

Rhoda [a lecturer in a bridging course and a PhD candidate] also devotes time in her classes discussing the expectations placed on students to succeed and to negotiate for community members with various agencies within a few weeks of enrolment.... 'This instantly places huge expectations on them'. Rhoda teaches her students to look at their community stresses and obligations objectively. So explaining community helps explain why it is so hard for Aboriginal students at university and her students often respond with 'I haven't ever thought about that'.

Related to this demand is the cultural remit whereby Aboriginal people family responsibilities cannot be ignored. Attendance at funerals and urgent family matters must take priority thus competing with study time and attention and these demands create an emotional need that staff should understand.

Students will also experience covert and overt racism and, as one interviewee explained, 'Each bit of racism takes slices off you' (see Liliane's story):

Liliane [a unit coordinator] is aware that her students meet obstacles everyday, so they need to be strong: 'Even if they are valued at home, they know that they are not valued outside. They may have been told at school that they will never achieve anything.... Each bit of racism takes slices off you'.

Our survey data contained considerable data about experiences of racism, for example, 'having to deal with racism and lack of understanding of Aboriginal issues', most of which was generated by non-Aboriginal students. Students reported 'overhearing racist comments from other students' or that 'racism has been a bad experience with dealing with some university students [who] can't get past stereotypes and tar every Indigenous person with the same brush'. It was also noted that students' racist comments were often ignored by teaching staff and there was report of 'prejudice delivered by the lecturer' and at the post-graduate level of 'being ridiculed, laughed at and ignored by my post-graduate supervisor'. One student mentioned having complained about racism within their Aboriginal centre which they then felt had negative repercussions:

'... having to complain about discrimination within the indigenous student services unit. Opportunities were being withheld from some students and I found out and made a formal complaint. Although I know I did the right thing I feel I am now seen as a trouble-maker even though the party I complained about was found to have done the wrong thing and is no longer at the uni'. 
or they have felt excluded because of their appearance:

'I haven't been able to connect with the Indigenous university community because I do not have traditional Aboriginal features'.

Many students are surprised and offended to see that acknowledgement of the existence of Aboriginal people and Aboriginal knowledge, in appropriate courses, is sometimes totally absent due to dominant western perspectives.

One student expressed frustration at the need to attribute his/her cultural knowledge to academic sources:

'I have found for myself that my culture plays a large part in the way I think and feel. I have a deep wisdom that I can tap into to bring forth knowledge, I feel frustrated to have to validate this with referencing someone who I have never met before to qualify my understandings. I then become frustrated with myself because I know I have to code shift so the lecturer receiving my work will think that I have done my home work simply by the way I present it rather than by the way I am. I understand many people would also go through these feelings and it doesn't only affect Indigenous students, though I feel so attuned to my cultural knowledge that the University construct at times feels like a complete insult to being human'.

These experiences inspired advocacy in one student who was shocked at the behaviours at her university and was influenced to attend to 'student rights and the future of Aboriginal community attending universities' hoping that 'changes can be made with good policy and education'.

More unfortunate, however, was the expectation reported in our study on the part of lecturers and tutors that Aboriginal students could fill in for the staff member's own lack of knowledge:

'At times I feel that being the only Aboriginal student in the class that you become the 'expert' on all Aboriginal which not only isolates you but you become a 'target' for all those who want knowledge'.

This expectation also comes from fellow students:

'Mainstream staff and students expect me to be the expert on every Aboriginal issue, and to speak on behalf of all Aboriginal people'.

This expectation of expertise can cause discomfort for students who feel torn between wanting to educate colleagues and the cultural convention that one Aboriginal person cannot speak for others. More important is the possibility that a student does not have the knowledge or the permission to speak on the topic. One student, who described herself as having been removed from her culture, recalled 'always having to explain the history and cultural context when I have had to learn these things myself'. Emotional stress can therefore be caused when one's identity is threatened in the pull between western education and one's own culture. One staff participant, Stephen, sees the importance in having appropriate knowledge:

Stephen [a research fellow and former teacher at his University's Aboriginal centre] finds that knowing the history and being able to discuss the policies and events that have affected Aboriginal people provides a commonality with students and 'takes the heat out of the discussion'.

Although such issues come at an emotional cost to some, others saw this as an opportunity to provide the "wealth of Aboriginal knowledge and experience' that they had accrued growing up in an Aboriginal culture. For example, one student described how he/she liked 'working with non-Indigenous university students and giving them a broader understanding about Indigenous people and breaking some of the stereotypes down by being myself'. Another student saw advantages in being from a minority group and believed that his/her education will help to overcome current disadvantages:

'By being a different colour to the dominant social group makes me what Malcolm X once said "a FLY IN THE MILK", being a minority and all. Also by being a minority gives me certain knowledge that the dominant social group don't have and that's a culture and history longer than theirs. By being a minority I am also not subject to certain favours in societal life. By being a minority I am also making a change for my people and being a role model for younger generations to see that our people are great and are achievers and academics like the dominant social group'.

Yet other students reported having experienced overt exclusion in classes and denigration of their contributions to discussions. Staff participating in our study claimed that Aboriginal students need to show persistence and resilience: the 'tough students will have an insight into the value of studies' (see Jean's story below) and will succeed in spite of numerous difficulties: 
Successful students in Jean's bridging course classes show persistence, they still come to class even though they are not sure, they keep at it; they ask questions and are not put down because they don't know, so next time they will ask again: 'Although it's tough, they keep on coming'. Jean sees that 'tough students will have an insight into the value of studies, they will ring and say they can't get in, but my door is always open for them to comeback with medical certificates, for deferrals, missed materials. [They] are proactive and want to look after their spot'.

Nonetheless many will need strong emotional support to stay at university and in these cases staff from their Aboriginal centre or other institutional support can provide this. For example, one student recalled his experience of racism in his business classes where most of his classmates were from south-east Asia and did not understand Aboriginal culture. 'Most of their perceptions came from Australian students who are also quite ignorant'. There were jokes about him being Aboriginal and he felt excluded because of his heritage. The student complained to his tutor who was also of south-east Asian decent and had only been in Australia for a few years, but no action was taken. Now this student does most of his work at the Aboriginal centre where he has been happy with the support.

Emotional needs can be addressed in a number of ways, with awareness amongst all university staff members being the first step. Awareness also extends beyond staff to the students. To this end, one staff member described how he tackles these sensitive issues in his classes:

Karl [a lecturer in Aboriginal Studies] has his groups examine who you are as an Aboriginal man/woman and how you keep that man/woman at university, for example, 'How do you handle being the only black (or white) person in the class or group?'.

Emotional needs can be addressed with definitive policies to ensure equity. To date university investment in equity has been the purview of disability services and not necessarily of Aboriginal centre's. At the same time there remains a need for flexibility and understanding within universities regarding the circumstances that Aboriginal students may encounter during their studies. Clearly there is also a need for professional support and structures within universities to enable this to be provided.

\subsection{Motivational needs}

Like all university students, the cohort that participated in our study described their need to be motivated. Some found they were able to draw on an internal 'drive to study', to 'learn as much as they can', but they highlighted the need to have a passion for what they were learning. Our staff participants noted that their students needed to find a personal connection with their course to apply themselves. As a result, appropriate enrolment was important and it was reported several times in the data that students were not given adequate advice upon enrolment or that admissions staff assumed that they would want to enrol in Aboriginal studies rather than in more professionally oriented courses (see John's story below):

John [a coordinator of ITAS (Note 5) tutoring] finds that some programs facilitate failure. For example a student may have been advised to enroll in a subject that he/she is not suited for. So it takes a lot of negotiation to keep a student at university when they may not be suited for it at all: 'Arts students are often channeled into Indigenous units where the content includes a lot of death and mayhem and is very emotional for students who may do better doing other units'. John therefore advocates a clearer policy on admissions.

Secondary schools were also mentioned as not providing students with university options and sometimes directing them to low level courses which would not lead to G8 (Note 6) university entry. The call for greater secondary school commitment seems to remain in spite of numerous programs that have been developed to attract more Aboriginal secondary students to university. (For example, Australian Indigenous Mentoring Experience (AIME) program (http://aimementoring.com); Engineering Aid Australia (http://www.engineeringaid.org/about-us/); The Stronger Smarter Institute (http://www.strongersmarter.qut.edu.au/index.jsp); University of Newcastle Indigenous Medical Entry Program; Bachelor of Medicine - Joint Medical Program (http://www.newcastle.edu.au/joint-medical-program/indigenous-students/); the University of Western Australia Year 12 seminars and subject specific camps for Years 9 to 11; and the ACT (Note 7) principals' recommendations).

From our data it appeared that mature age students were generally motivated by their desire to provide a better future for their children or to enhance their own quality of life (see Sharon's story below):

Sharon is a 23-year-old single mother who is currently enrolled in her second year of early childhood education. Once her child started pre-primary, she was able to realise her ambition and attend university. She enrolled in the bridging course and found it very easy. The hardest part was her transition into 
mainstream university. Nonetheless she found that all her classmates were very inclusive and that her experience of raising her own child helped in her studies. In particular she has found one tutor to be extremely encouraging, often getting her to talk to the other students about bridging the gap between parents and early childhood educators. Sharon is excited to continue her degree and to help other young mothers.

For those with employment experience, a number wanted to improve their qualifications for promotion. As one student, Narelle, noted, there is 'more to life than just labouring and working for middle managers earning a basic wage':

Narelle is a 45 year old business student. When her youngest son enrolled at university, he began to influence his mother to also enrol at university as she had always wanted to set up her own business, but was never sure how to. Persuaded by her son, Narelle attended an information night for mature age students where she fell in love with the independence that tertiary education promised. She subsequently enrolled as a mature age student in the business school majoring in management.

Others were motivated by the betterment of Aboriginal people - 'to be engaged in change' and were attracted to professions such as law, medicine, nursing and business. For them academic success was also the means to "change everyone's ideas on what our people can do':

'[I enrolled] because everyone said I would never be able to do it and I wanted to change everyone's ideas on what our people could do. I thought if I could educate myself then maybe I could educate others and improve our health outcomes, and I could convince other kids they can do it as well, that it is important that everyone try to do what they want in life and they should not let others hold them back'.

Several participants explained that in order to achieve academically, they needed a strong 'sense of self'. It was indicated that a lack of this personal quality challenged their ability to complete their degree. For others past experiences negatively impacted on their resilience and ability to continue with their studies. For instance, students' own educational histories where 'they may have been told at school that they will never achieve anything' (see above Liliane's story) can be a deterrent to motivation as explained in Karl's case study:

Karl [a lecturer on Aboriginal Studies] has observed that Aboriginal students have stereotypical (and even negative) ideas of university, so they need to build their self-esteem first. They have not been encouraged to learn, have expectations of unsuccessful outcomes, fear the judgment of others, and are often frightened of the large numbers of students at university and in their classes.

However, one bridging course instructor did not tolerate 'poor fella me' attitudes and aims to show her students that 'they are not hard done by', illustrating 'what they can bring to the learning situation', to value their existing knowledge so that non-Aboriginal people will also value it. This participant recommended using role models from among the Aboriginal community as means of motivation. However, she sounded a note of caution, suggesting the need to get away from common practice of drawing role models from the sport. Instead she introduced her students to the life of inventor, philosopher and scholar, David Unaipon.

\subsection{Financial needs}

Financial need consistently emerged as one of the most pressing in our research. This is consistent with other research in the field, for example Brady (2012), suggests that one of the main causes of attrition is the pressure that Aboriginal students experience financially:

'Students who have been successful in obtaining university controlled housing may not be able to move into their accommodation if the funds are not made available at the beginning of the semester. Alternatively, if students are seeking to live off-campus they are in desperate need of funds to pay bonds and rent well before they receive their payments. Indigenous students generally do not have families who can afford to assist them and they rely on the support centres and charities to help them. This creates additional stress on Indigenous students who are facing the challenges of entering university study while also struggling with the fundamental need for housing' (Brady, 2012, p. 4).

Almost all students who postpone their careers and subsequent earning capacity in order to study will face some sort of financial hardship and, more often than not, go into debt to complete their courses. For Aboriginal students, however, this hardship is augmented by obligations to extended family which may include health, housing and general expenses. In the following extract from our cases studies, Courtney describes her commitment to study and the sacrifices required: 
Both Courtney and her husband are on low incomes and are helped by government cadetships and scholarships. The cadetships pay for all units passed, so reduce the amount owing on HECS (Note 8) fees at the end of the degree. It also means that they are guaranteed jobs. Nonetheless, because of the high cost of childcare and rent, they still have to live off their savings... Even though they struggle with finances, she still thinks 'it is worth it'.

While many Aboriginal students have not been previously employed and will not have had the opportunity to set by funds to see them through university, Jessie, as the eldest of five siblings, sees it as her responsibility to continue to work to help support the family:

Jessie is a full time student who leads a very busy life. ... As the eldest of five children, she also 'basically works full time' to help support the family. Jessie managed to complete Year 12 although her attendance was poor as she had to look after her younger siblings when her mother went back to shift work. Jessie is the first in her family to complete Year 12 and the first to go to university.

Aboriginal centres, and universities more generally, can and sometimes do, respond to this need to provide financial support for Aboriginal students by way of funds to purchase books, to travel and to help pay for accommodation. However, it was reported that, sometimes, Aboriginal students are not advised of these support mechanisms or that the economic rationalism adopted by universities means that such funding is no longer available. In order to ensure that Aboriginal students are thoroughly aware of the support that is available to them, it is essential that centres are kept well informed of their enrolment. With more students enrolling who have completed their secondary education rather than entering a bridging course - this becomes even more important.

As reported by the Indigenous Higher Education Advisory Council (IHEAC) (2006), '[e]ffective student support, in its various forms including financial, social and academic support, is integral to unlocking the problems of Indigenous access and participation' (p. 6). Social and economic factors converge to cause high rates of attrition as '[m]any Indigenous students study under economic pressure, often because they are of mature age and have partners and families' (p. 6). Additionally, Federal government scholarships are critical for Aboriginal students who most often need to relocate (sometimes with their young families) in order to attend university. Timely payments of financial support and affordable housing are therefore mandatory.

\subsection{Study needs}

The study needs of Aboriginal students may differ markedly from those of non-Aboriginal student cohorts. Firstly many Aboriginal students will not have the privilege of private time and space within their own homes, for example, a room of their own, a quiet study area, or an internet connection. Should a computer and internet access be available in the home, it is culturally appropriate that it is shared with siblings and other family members. Hence access to these facilities needs to be provided by Aboriginal centres.

In the following extract Samantha describes the study benefits she has found through living in university student accommodation.

Samantha is a first year nursing student. As she is from another part of her state, she lives in the college accommodation that the university provides. Samantha was very nervous before moving as she had never lived away from her close-knit family and did not know anyone studying at the university or living in the region. However, once she arrived at the university, she found the college system extremely helpful for her transition to living independently and studying at a tertiary level. The orientation activities helped her to meet new students. At first, Samantha felt overwhelmed by the amount of work and the sheer size of classes. Fortunately, she found lecturers were very approachable and tutorials helped to reinforce her learning. Most important to Samantha's success was having a room-mate who encouraged her learning, and who organised a specified study time.

Student computer facilities have been established in all universities, however, the students interviewed for our study, whether through shyness or disinclination to mix with non-Aboriginal students, valued the facility in their own centre, while some noted that there were not enough computers or that they were not working when needed. Several advantages arose from working in the centre including new students being able to mix with, and get help from, those ahead of them, and the environment being culturally safe. Further, the centres provide bridging or enabling programs aimed at teaching study skills and as well as academic literacy. Sally, the coordinator of such a program, describes these students' needs:

Many Aboriginal students coming to the program are mature age, most in their 20s, who have a considerable gap in their basic study skills: 'That gap is hard to bridge, the students need motivation, not 
knowing how to go about studying is a hindrance'. Learning skills workshops [in Sally's program] are voluntary but ITAS tutors might also prepare students for study.

The study needs for our student cohort also required flexibility. Many had small children who needed to be cared for after school. This also made study difficult in the evenings. To address these issues, one participating centre structured the contact hours of its bridging program to accommodate family commitments. 'For example, lectures are all between 10-11am and tutorials between 1-3pm. In between the centre resources are available for independent study as most students will do their work at the university rather than at home where family commitments take precedence'. In the following case study extract, Jessie explains her preference to study at university and the benefits that this provides:

Jessie's family is supportive of her studies. She doesn't study at home, but comes back to the Aboriginal centre to study in the evenings and tries to finish up by midnight. She often studies with her cousin who is doing a Bachelor of Teaching. They read each other's assignments and discuss ideas.

However, family involvement and responsibilities can frequently be a distraction from studies as evident later in Jessie's case study:

Jessie has now nearly completed her second year but notes that things 'have gotten a bit shaky' this semester. The main threat to completing her degree is family: they place a high demand on her time which causes her to lose her focus. The second semester in first year wasn't good either for the same reason. Jessie, therefore, believes that Aboriginal students need more time and more help. Although she uses an ITAS tutor, she needs more help than a tutor can give her.

As one student explained:

'Family and community are an essential part of being Aboriginal. They come first and it is often a challenge to fit university around these'.

For some, returning to university after many years - whether years of child rearing, unemployment and/or work, or even prison terms - was a daunting experience and these students in particular needed to overcome their 'shame'. The term shame refers to the debilitating embarrassment and shyness experienced by Aboriginal people when they are the object of either positive or negative attention and especially in the company of persons of authority (e.g., educators, employers, police officers) (Eagleson, Kaldor \& Malcolm, 1982; Harkins, 1990; Author, et al., 2012). It was noted in our data that shame can be induced by being required to participate in tutorials, by handing in assignments, by contributing to online discussions, and even by asking for help. Indeed it was reported that some students are so shamed by their own perceived inadequacy that they do not submit completed assignments. Manifestations of shame include avoidance of eye-contact and reticence, and for some withdrawal from studies. Obviously, given the possibility of being the only Aboriginal student in a class; of being requested to provide knowledge about Aboriginal culture and/or perspectives on an issue; or of experiencing covert or overt racism, it is not surprising that Aboriginal students will withdraw from study to avoid potentially shame-inducing situations (Oliver et al., 2012).

External students do not generally have the advantage of a centre's resources, particularly the comradeship that can develop with other students. Celeste describes how she has managed her external studies by developing local contacts:

Celeste finds that she can manage online study because she has found a way to collaborate with others. For example, she works with a friend enrolled in the same course, explaining things to each other and for preparing for tests. Her friend has also taught her about referencing. Celeste is mentored by her mother who has higher education degrees in Business, Arts and Indigenous Studies. She also has an ITAS tutor who works with her two hours per week in each subject, but she is resourceful with her hours, saving them for subsequent weeks when an assignment is due. She has only used her university's support services once when a journal article on e-reserve was not available, but she worked out how to access it another way while on the phone. She later received an email to say that the problem had been fixed. She has also emailed her lecturer on occasion for help with terminology.

As an alternative to both full-time and external study, which has been introduced at numerous Australian universities, is the Block Release program. Several students indicated that they preferred this method of study. Lena, the coordinator of the Block Release program at her university, describes how it works: 
Block Release involves 2 weeks spent on campus with 3 hours of face-to-face sessions with lecturers, plus lectures. Lecturers are also available after hours if extra time is needed. This arrangement suits many students who have families - they are away from family demands and can focus on their studies - many get their assignments done during this time. Some students also form study groups in their hometowns. Nonetheless, some students cannot get time off work or are hindered by family issues and are unable to attend Block Release so might use the Reverse Block option whereby the lecturers travel to see the students.

\subsection{Literacy needs}

Apart from one student reporting her need to make her writing 'more academic', there was little reference to literacy needs by the students in our study. Instead, their main concerns appeared to be succeeding in the face of family, health and financial issues. This could have been because a number of students had parents or in-laws with academic qualifications, or that the students themselves had set up strategies such as reading each other's assignments.

However, staff noted that bridging students needed to improve their literacy levels, and many were aware of this need. Staff teaching in bridging programs in particular felt the need to expand their students' vocabulary, critical skills and general knowledge, creating quizzes and shared tasks to meet these needs and which the students enjoyed. At the same time a number of our participants, whilst acknowledging literacy needs, indicated that the type of academic writing instruction that is available to students could be made more interesting.

\subsection{Transitional needs}

Transitional needs are those needs that we see as assisting students to settle into university life. Not surprisingly, transitional success can contribute to improving retention and completion, while a negative experience during the transition period will obviously trigger discomfort and the possibility of attrition.

Our data has provided evidence of successful transition into higher education and positive experiences of support by Aboriginal centres and of university generally showing that in many cases the transitional needs of Aboriginal students are being addressed:

'I do not feel unwelcome or uncomfortable when I attend my lectures on campus'.

'Everyone I engage with at University (staff and students) makes me feel welcome and ensures everything is being done for me to fulfil my studies. I am constantly updated with information from the staff and I know the door is always open if I need anything'.

'Going to Orientation and using the campus facilities really makes me feel part of university life, it's the atmosphere and the knowledge that every student at university is there because they want to be'.

'I feel I am part of the University as I receive magazines, regular emails and information about what is going on at the University. I also have regular correspondence with other students online and the University provides opportunities for students in other states to meet up and get to know staff and other students'.

However the data have also captured a cross-section of Aboriginal student experience showing a range of difficulties. We found that Aboriginal students were frequently overwhelmed and apprehensive by the university environment with its tall buildings, large class sizes, and general busy-ness. Nonetheless they were generally keen to be recognised as members of the university community and to know that they were valued as much as non-Aboriginal students. They were keen to learn as much as they could and to benefit from the better future opportunities which would result from academic and/or professional qualifications.

By contrast, there were, for some, barriers to overcome in the process of transition. Several staff regretted the fact that little contact occurred between Aboriginal and non-Aboriginal students. This was particularly the case for bridging students who are often isolated by the peripheral location of their centre on campus. To address these needs, centre staff would take students to experience the campus facilities, for example, to the bookshop, cafeteria, or library. Another staff member, Liliane, arranged for non-Aboriginal students and Aboriginal students to meet up in order to break down the barriers:

Liliane [a unit coordinator] also brings her non-Aboriginal students from her education units to the centre to meet her Aboriginal students, 'many are afraid of meeting an Aboriginal person, some (e.g., overseas students) don't believe they exist or local students may never have seen one'.

A further staff member arranges for her students to contribute to cultural induction programs either within or outside the university to make contact with the non-Aboriginal population: 
Lisa [a lecturer in a bridging program] and her students have given successful cultural induction entitled What makes Indigenous people tick to audiences of over 100 people from the police department, a girl's college, nursing staff and migrant groups. Lisa and her students have also delivered cross-cultural training entitled Closing the Gap in your own Nursing Practice to the university Nursing faculty. Currently she is collaborating with the Psychology and Pharmacy faculties.

An important part of the transition process for Aboriginal students is to meet their ITAS tutor. John is coordinator of his university's ITAS program and explains the process in his case study:

Most of the ITAS tutors at John's university are higher degree research students, otherwise they must be at least two years ahead of the student they will support, but there is a high turnover of tutors. Students and tutors are paired according to subject areas and/or similar course content, although content changes continually.

However, sometimes difficulties occur in the organisation of the ITAS program and students might be left unsupported during their initial critical weeks at university.

Another transitional need for students is contact with supportive people. Staff member Lorraine describes the importance of this need:

Lorraine is a lecturer and coordinator of an Aboriginal Education unit within an education degree. She maintains that Aboriginal students 'need to be listened to' and 'need someone to talk at. Without this contact with people they don't stay - it's "I'm out of here"'. She sees the need for buddy systems and liaison officers in continual contact with students to help them manage their transition - at her university the liaison position was not currently filled. Aboriginal students, Lorraine maintains, 'want to have a connection with what they learn and who teaches it, without that they feel undervalued'.

As mentioned above, a major transitional need is coming to terms with western perspectives on Aboriginal history and culture. In spite of their success, some students still felt the pressure of this experience. For example, 'Being an Aboriginal tertiary student means living in a constant realm of cultural tension, pulled between Western education and my cultural identity'.

Coming to university means learning about how other people view Aboriginal people - however misinformed this view may be. As explained by Nakata (2006), the study of Aboriginal society and culture is not so much the facts of 'histories, cultures, or contemporary issues alone but necessarily, given historical circumstances, the study of how we have been studied, circumscribed, represented and how this knowledge of us is limited in its ability to understand us' (p. 272). The textualisation of Aboriginal knowledge over time has meant that "the "knowers" of that knowledge are separated out from what comes to be "the known". It is separated from "the practices that constantly renew its meaning in the here and now' (Nakata, 2007, p. 9). Not surprisingly, therefore, much of what is taught about Aboriginal history and culture could be totally unrecognisable to the current cohort of Aboriginal students.

By default, studies in Aboriginal culture have been 'mediated through the lens of western culture' (ACER, 2011) which excludes Aboriginal perspectives and experience, however this transmission is being increasingly contested by Aboriginal and non-Aboriginal people generally. We are now challenging the binarisms and dualistic modes of thought... We evoke Indigenous knowledge to challenge the linearity of Western paradigms privileged in the academy' (Sefa Dei, 2008, p. 8). This approach, to follow Herbert (2010), empowers students (both Aboriginal and non-Aboriginal) to become agents of change in the broader Australian context.

Rigney (2012) suggests that the underrepresentation of Aboriginal academics in university has led to the failure to promote Aboriginal knowledge. In 2006, the Indigenous Higher Education Advisory Council (IHEAC 2006) also noted the low numbers of Aboriginal staff in our universities particularly in governance and management roles (p. 5) and the 'lack of visibility of Indigenous cultures and knowledges on campus' (p. 4). Indeed, for some universities the existence of an Aboriginal centre obviates the need for further focus on Aboriginal recognition and knowledge inclusion - 'Centres are the Aboriginal and Torres Strait Islander strategy' (Walter, 2012, p 3).

Our data, and the current literature, demonstrate a strong need for more Aboriginal faculty staff in order to acknowledge the parallel knowledge system that has survived in this country, even in the face of considerable efforts in recent history to extinguish it. Recognising and valuing of this knowledge is an initial step towards generating more successful transition for Aboriginal students. 


\section{Conclusion}

In this paper we have carefully analysed the needs of Aboriginal and Torres Strait Islander students within our higher education institutions. Although all new students have specific needs in order to move successfully into university, those needs of Aboriginal students are more persistent and less easy to overcome. Family responsibilities, for example, cannot be easily set aside, but will continue to drain the student emotionally, motivationally and even financially not only during transition, but throughout one's degree. Similarly the emotional stress of crossing cultural boundaries while maintaining allegiance to one's own culture and identity also places additional strain on Aboriginal students and comes as a shock to newly enrolled students at the point at which they wish to be accepted and valued.

Our research shows that universities need to respond to a range of study pressures which have been previously recognised by other scholars in the area. Sadly evidence of discrimination, reported by Sonn et al. in 2000, seems not to have changed. Familial responsibilities - a strong cultural factor - are still distracting for students as reported by Andersen et al., in 2008. Greater recognition of these responsibilities across the university is still required. Moreover, at several centres it was reported that financial constraints experienced by students may well have been exacerbated since earlier studies due to university economic rationalism. Additionally, although steps have been made to incorporate appropriate recognition of Aboriginal knowledge and experience in relevant subject areas at numerous universities, there were still calls in our data for improvement in this area.

With the development of Australia's mining industry, opportunities for Aboriginal students to work in these and related industries have become available in the remote areas where many live. Our universities should, therefore, be leading the way in preparing our Aboriginal population for these new employment opportunities. This includes ensuring that these students can benefit from equitable access to, and success in, the relevant areas of study by seriously addressing their numerous and complex study needs.

To reiterate Devlin's (2009) important message, we concur that "[i]n order to improve Indigenous equity, we must understand the failures that have occurred and continue to occur in relation to Indigenous higher education equity" (our italics). We hope that a recent study entitled Indigenous Cultural Competency in Australian Universities, conducted by Universities Australia (a peak body representing Australia's 39 universities) in collaboration with the Indigenous Higher Education Advisory Council will go some way to addressing the issues identified in this paper, and that a report from this project: National Best Practice Framework for Indigenous Cultural Competency in Australian Universities will guide policy for addressing Aboriginal university student needs in the future.

\section{Acknowledgements}

The authors of this paper are particularly grateful to the Office of Learning and Teaching (Department of Education. Employment and Workplace Relations) (DEEWR) for providing the funding for this research. We also acknowledge the valuable contributions of our research team and our wider research network: Ellen Grote, Guido Posthausen, Rose Lovelock and Trudy Avlonitis. Finally we wish to thank all those staff and students who participated in our study and provided us with such a rich source of data.

\section{References}

Anderson, J. (2000). Teaching information literacy skills to Indigenous adults. In D. Brooker (Ed.) Concept, Challenge, Conundrum: From Library Skills to Information Literacy. Proceedings of the Fourth National Information Literacy Conference (pp. 35-39). Adelaide: University of South Australia Library.

Australian Council for Educational Research. (2012). Literature Review relating to the current context and discourse of Indigenous Tertiary Education in Australia. In L. Behrendt, S. Larkin, R. Griew, \& P. Kelly (Eds) Review of Higher Education Access and Outcomes for Aboriginal and Torres Strait Islander People Final Report. Canberra, Australian

Government. http://www.innovation.gov.au/HigherEducation/IndigenousHigherEducation/ReviewOfIndigenousHigherEducat ion/Pages/default.aspx

Barney, K. (2013). 'Taking your mob with you': giving voice to the experiences of Indigenous Australian postgraduate students. Higher Education Research \& Development, 32(4), 515-528. http://dx.doi.org/10.1080/07294360.2012.696186

Bin-Sallik, M. (2003). Cultural safety: let's name it! Australian Journal of Indigenous Education, 32, 21-28.

Brady, W. (2012). Indigenous student support in Australian universities. In L. Behrendt, S. Larkin, R. Griew, \& P. Kelly (Eds) Review of Higher Education Access and Outcomes for Aboriginal and Torres Strait Islander People Final Report. Canberra, Australian Government. 
http://www.innovation.gov.au/HigherEducation/IndigenousHigherEducation/ReviewOfIndigenousHigherEducat ion/Pages/default.aspx

Department of Education, Employment and Workplace Relations (DEEWR). (2009). Number of Full-time and Fractional Full-time Indigenous Staff by State, Higher Education Provider, Function and Gender. http://www.innovation.gov.au/HigherEducation/HigherEducationStatistics/Pages/default.aspx

Department of Industry. (2012). Summary of the 2012 full year higher education student statistics. http://www.innovation.gov.au/highereducation/HigherEducationStatistics/StatisticsPublications/Pages/default.as $\mathrm{px}$

Devlin, M. (2009). Indigenous higher education student equity: Focusing on what works. The Australian Journal of Indigenous Education, 38, 1-8.

DiGregorio, K.D., Farrington, S., \& Page, S. (2000). Listening to our Students: Understanding the factors that affect Aboriginal and Torres Strait Islander students' academic success. Higher Education Research \& Development, 19(3), 297-309. http://dx.doi.org/10.1080/758484344

Eagleson, R. D., Kaldor, S., \& Malcolm, I. G. (1982). English and the Aboriginal Child. Canberra: Curriculum Development Centre.

Harkins, J. (1990). Shame and shyness in the Aboriginal classroom: A case for practical semantics. Australian Journal of Linguistics, 10, 293-306. http://dx.doi.org/10.1080/07268609008599445

Herbert, J. (2005). 'Owning the discourse: Seizing the power!', Australian Association for Research in Education. University of Western Sydney. http://www.aare.edu.au/05pap/her05217.pdf.

Herbert, J. (2010). Indigenous studies: tool of empowerment within the academe. Australian Journal of Indigenous Education, 39, 23-31.

Indigenous Higher Education Advisory Council (IHEAC). (2007). Improving Indigenous Outcomes and Enhancing Indigenous Culture and Knowledge in Australian Higher Education. Report to the Minister for Education, Science and Training.

James, R., Anderson, A., Bexley, E., Devlin, M., Garnett, R., Marginson, S., \& Maxwell, L. (2008). Participation and equity: A review of the participation in higher education of people from low socioeconomic backgrounds and Indigenous people. Report prepared for Universities Australia: Centre for the Study of Higher Education University of Melbourne. http://dro.deakin.edu.au/view/DU:30006777?print_friendly=true

Malcolm, I., Author and Hayes, G. (2002) 'It's just totally different world to what you're used to': The Application of Indigenous Skills to University Teaching and Learning. Mount Lawley, Western Australia: Centre for Applied Language and Literacy Research in conjunction with Kurongkurl Katitjin, The School of Indigenous Australian Studies, Edith Cowan University.

Nakata, M. (2006), Australian Indigenous Studies: A Question of Discipline. The Australian Journal of Anthropology, 17(3), 265-275. http://dx.doi.org/10.1111/j.1835-9310.2006.tb00063.x

Nakata, M. (2007). The cultural interface. Australian Journal of Indigenous Education, 36 (Supplement), 7-14.

Nakata, M., Nakata, V., \& Chin, M. (2008). Approaches to the academic preparation and support of Australian Indigenous students for tertiary studies. Australian Journal of Indigenous Education, 37 (Supplement), 137-145.

Oliver, R., Grote, E., \& Rochecouste, J. \& Exell, M. (2012). Addressing the language and literacy needs of Aboriginal high school VET students who speak Standard Australian English as an additional language. The Australian Journal of Indigenous Education, 41(2), 229-239. http://dx.doi.org/10.1017/jie.2012.23

Oliver, R., Rochecouste, J., Bennell, D., Anderson, R., Cooper, I. \& Forrest, S. (2013). The Transition of Aboriginal and Torres Strait Islander students into higher education. Office of Learning and Teaching, Canberra: DEEWR.

Pechenkina, E., \& Anderson, I. (2012). Background paper on Indigenous Australian higher education: trends, initiatives and policy implications. In L. Behrendt, S. Larkin, R. Griew, \& P. Kelly (Eds) Review of Higher Education Access and Outcomes for Aboriginal and Torres Strait Islander People Final Report. Canberra, Australian

Government. http://www.innovation.gov.au/HigherEducation/IndigenousHigherEducation/ReviewOfIndigenousHigherEducat ion/Pages/default.aspx 
Rigney, L-I. (2012). Indigenous higher education reform and Indigenous knowledges. In Behrendt, L. et al. Review of Higher Education Access and Outcomes for Aboriginal and Torres Strait Islander People Final Report. Canberra, Australian

Government. http://www.innovation.gov.au/HigherEducation/IndigenousHigherEducation/ReviewOfIndigenousHigherEducat ion/Pages/default.aspx

Rodgers-Falk, P., \& Vidler, R.J.P. (2012). Growing the number of Aboriginal and Torres Strait Islander Law Graduates: Barriers to the Profession. In L. Behrendt, S. Larkin, R. Griew, \& P. Kelly (Eds) Review of Higher Education Access and Outcomes for Aboriginal and Torres Strait Islander People Final Report. Canberra, Australian

Government. http://www.innovation.gov.au/HigherEducation/IndigenousHigherEducation/ReviewOfIndigenousHigherEducat ion/Pages/default.aspx

Sonn, C. C., Bishop, B. J., \& Humphries, R. (2000). Encounters with the dominant culture: Voices of indigenous students in mainstream higher education. Australian Psychologist, 35(2), 128-135. http://dx.doi.org/10.1080/00050060008260334

Stewart, J. (2002). The relevance of the 'learning styles debate' for Australian Indigenous students in mainstream education. Australian Journal of Indigenous Education, 30(2),13-19.

Universities Australia. (2011). National Best Practice Framework for Indigenous Cultural Competency in Australian Universities. Canberra: Universities Australia.

Walter, M, (2012). Embedding Aboriginal and Torres Strait Islander presence: opening knowledge pathways. In L. Behrendt, S. Larkin, R. Griew, \& P. Kelly (Eds) Review of Higher Education Access and Outcomes for Aboriginal and Torres Strait Islander People Final Report. Canberra, Australian Government. http://www.innovation.gov.au/HigherEducation/IndigenousHigherEducation/ReviewOfIndigenousHigherEducat ion/Pages/default.aspx

\section{Notes}

Note 1. Throughout this paper we have used the term 'Aboriginal' to refer to both Aboriginal and Torres Strait Islander students.

Note 2. This research was undertaken by a team of researchers from four Australian universities in response to a call to identify success and best practice in facilitating the transition of minority Aboriginal groups into tertiary education. The project was funded by the Office of Learning and Teaching (OLT), within the Department of Education, Employment and Workplace Relations (DEEWR).

Note 3. Australian Aboriginal and Torres Strait Islander peoples (i.e., the Indigenous inhabitants of the islands between Australian and New Guinea) are referred to collectively under the term Aboriginal in this paper.

Note 4. Although not representative of the total Australian Aboriginal tertiary student population, which in 2012 was 12,632 (Department of Industry, 2012), this number was representative of the wide range of student enrolled at the participating universities' Aboriginal centres.

Note 5. The Indigenous Tutorial Assistance Scheme (ITAS) provides funding for additional tuition for Aboriginal students studying at tertiary level.

Note 6. The Group of Eight (Go8) is a network of Australian universities with intensive research records as well as academic and professional courses.

Note 7. Australian Capital Territory.

Note 8. Higher Education Contribution Scheme (HECS) is an Australian student's contribution to the cost of tuition fees and can be paid upon enrolment or deferred until employment is gained. 